\title{
Achievement of NKF/K-DOQI Recommended Target Values for Bone and Mineral Metabolism in Incident Hemodialysis Patients: Results of the FARO-2 Cohort
}

\author{
Mario Cozzolino ${ }^{a}$ Piergiorgio Messab ${ }^{b}$ Diego Brancaccio $^{c}$ Giuseppe Cannella ${ }^{d}$ \\ Piergiorgio Bolasco ${ }^{e}$ Marina Di Luca ${ }^{f}$ Anna Maria Costanzo $^{g}$ \\ Umberto di Luzio Paparattig Vincenzo Festag Giuliana Gualbertig \\ Sandro Mazzaferro ${ }^{\mathrm{h}}$ on behalf of the FARO Study Group \\ ${ }^{a}$ Renal Division, Department of Health Sciences, University of Milan, San Paolo Hospital, bephrology, Dialysis and \\ Renal Transplant, Fondazione Ca' Granda IRCCS-Policlinico, 'Dialysis Unit 'Simone Martini', Milan, ${ }^{d}$ Department of \\ Nephrology, San Martino Hospital, Genoa, ${ }^{\mathrm{e} T e r r i t o r i a l ~ N e p h r o l o g y}$ and Dialysis Unit, ASL Cagliari, Cagliari, ${ }^{f} U O C$ \\ Nephrology Dialysis Ospedali Riuniti Marche Nord, Pesaro, ${ }^{9}$ AbbVie SrL Italy, Campoverde, Latina, and hipartimento \\ di Scienze Cardiovascolari Respiratorie Nefrologiche e Geriatriche, Sapienza Università di Roma, Roma, Italy
}

\section{Key Words}

Mineral Bone Disorders · NKF/K-DOQI - Incident haemodialysis · Survival

\footnotetext{
Abstract

Background: Mineral Bone Disorders (MBD) is prevalent in hemodialysis (HD) patients and associated with increased cardiovascular mortality. The FARO-2 study evaluated the achievement of the NKF/K-DOQI guidelines on recommended target values for serum calcium (Ca), phosphorous (P) and intact parathyroid hormone (PTH) levels on survival in incident HD patients. Methods: Data were collected by questionnaire from 568 incident HD patients followed prospectively over a 3-year period from 26 Italian dialysis units. The cumulative probability of time-to-death for CKD-MBD treatment characteristics was determined by the KaplanMeier curves. Results: Serum PTH levels (median values at
}

6 months vs. 36 months; 225 vs. 254 pg/ml), Ca (8.8 vs. 8.9 $\mathrm{g} / \mathrm{dl})$ and $\mathrm{P}(5.1 \mathrm{vs} .4 .8 \mathrm{mg} / \mathrm{dl}$ ) were not significantly different at 6 months versus follow-up. The majority of incident HD patients (60-70\%) who were followed up for 36 months did not achieve the NKF/K-DOQI recommended target values. Survival rates were higher in patients on target for three parameters versus patients off target (survival at 24 months: at target $95.7 \%$ (95\% Cl: 84.0-98.9) versus not on target $71.1 \%$ (95\% Cl: $66.3-75.4, \mathrm{p}<0.01)$ ). The $30.1 \%$ of patients on target for three MBD parameters at least once during the follow-up period had better survival rates compared to those not reaching these targets (survival at 24 months: at least once $88.0 \%$ (95\% Cl: 81.9-92.1); 67.7\% (95\% Cl: 61.9-72.8, $\mathrm{p}<0.01)$ ). Conclusion: Our findings indicate that incident HD patients who achieved target levels (for three MBD parameters) for at least one visit have a lower risk of mortality.

(c) 2014 S. Karger AG, Basel

\section{KARGER}

E-Mail karger@karger.com

www.karger.com/bpu
(C) 2014 S. Karger AG Basel

0253-5068/14/0381-0037\$39.50/0
Mario Cozzolino, $\mathrm{MD}, \mathrm{PhD}$

Renal Division, Department of Health Sciences, San Paolo Hospital University of Milan, Via di Rudinì 8 IT-20142 Milan (Italy)

E-Mail mario.cozzolino@unimi.it 


\section{Introduction}

Despite therapeutic advances, mortality rates remain high among patients with chronic kidney disease (CKD), particularly those undergoing hemodialysis (HD) $[1,2]$. The main cause of mortality in these patients is attributed to cardiovascular-related diseases [2]. However, patients with CKD are also affected by mineral and bone disorders (CKD-MBD), resulting in abnormalities in serum calcium $(\mathrm{Ca})$, phosphorous $(\mathrm{P})$ and parathyroid hormone (PTH) [3]. Changes in mineral metabolism have also been associated with higher rates of both all-cause and cardiovascular-related mortality [3-15]. The majority of HD patients are also deficient in the endogenous hormone, 1,25-dihydroxyvitamin D (calcitriol) often contributing to increased secondary hyperparathyroidism (SHPT) and consequently abnormal levels of $\mathrm{Ca}, \mathrm{P}$ and PTH [16].

In 2003, the US National Kidney Foundation implemented The Kidney Disease Outcomes Quality Initiative (K/DOQI) international guidelines to establish target levels for serum PTH, Ca and P in an effort to help lower secondary hyperparathyroidism (SHPT)-related mortality [17]. Unfortunately, evidence suggests that these restrictive guidelines are difficult to achieve, especially over the long term $[18,19]$. Since these guidelines were implemented, there has been an increased awareness of SHPT, in addition to the introduction of newer treatment options in clinical practice. Furthermore, clinical guidelines are available for optimal levels of serum markers of CKDMBD, but target parameters are not achieved in many HD patients [20].

Among these, synthetic vitamin $\mathrm{D}$ receptor activators (VDRAs) have been developed, that are less hypercalcemic and hyperphosphataemic compared to exogenous administration of calcitriol and other vitamin D metabolites, and are efficacious in treating patients with CKDMBD $[21,22]$, and are now considered the standard therapy for CKD patients [23]. The use of VDRAs, such as calcitriol or the selective VDR activator paricalcitol, is also associated with improved survival in HD patients $[15,24-31]$.

Although several studies have examined the association between mineral levels and the impact of achievement of $\mathrm{K} / \mathrm{DOQI}$ mineral target ranges on mortality rates in $\mathrm{HD}$ patients $[3-6,8-15,19,31,32]$, only a few studies have been conducted to date on incident HD patients $[33,34]$. Furthermore, evidence indicates that in incident HD patients, mortality rates are higher in the early stages (first 3-4 months) of dialysis, warranting studies in this setting
[35]. Therefore, the aim of this analysis of the FARO-2 study, a sub-group of the original FARO study $[31,36]$, was to assess SHPT management and alignment with K-DOQI target ranges [17,37], on mortality rates on a subgroup of incident HD patients from the FARO study $[31,36]$.

\section{Materials and Methods}

\section{Study Design}

FARO-2 was undertaken in 26 dialysis centers across Italy. This observational study was performed on a subgroup of incident HD patients who participated in the FARO study (conducted between 2006 and 2007) [31, 36]. Subjects who started dialysis treatment during the FARO study, that is, those who had vintage dialysis of $\leq 8$ months were included. Data were collected retrospectively through the use of 6 questionnaires (4 questionnaires were collected during the original FARO study between 2006 and 2007) and 2 additional questionnaires were collected during 2008 in the present study (FARO-2). Data are presented by semester from the beginning of dialysis (irrespective of the moment in which the patient entered into the FARO study). The follow-up period for each subject is a variable and ranged from a minimum of 6 months to a maximum of 3 years. All patients provided written informed consent and the study was approved by all local ethic committees.

Achievement of MBD K-DOQI Recommended Target Values

For patients with stage $5 \mathrm{CKD}$ undergoing HD, the 2003 guidelines of the Kidney Disease Outcomes Quality Initiative (KDOQI) of the National Kidney Foundation were used [17]. The 2009 Kidney Disease - Improving Global Outcomes (KDIGO) guidelines were not yet available at the time this study was undertaken [38].

\section{Statistical Analysis}

The proportion of patients achieving K-DOQI ranges for any one of the biochemical parameters (PTH, Ca or P) was calculated every 6 months; the proportion of patients achieving target $\mathrm{K}$ DOQI ranges for all three parameters (tri-target) was also calculated likewise; the proportion of patients achieving tri-target at least once, was calculated over the entire follow-up period. Differences in the proportion of patients achieving target values over the study period were assessed by chi-squared for trend.

The Kaplan-Meier (KM) method was used to estimate the cumulative probability of all-cause mortality in all patients. KM survival estimates were also performed to assess the effect of achievement of K-DOQI target values on all-cause mortality. The KM survival analysis was performed at 24-month due to the low number of patients included in the last 12 months of observation. Given that the achievement of K-DOQI targets (for 'tri-target' and for 'at least once' on target) varies during the follow-up period, the risk time was divided into specific time contributions depending on when the K-DOQI target was achieved. Thus, survival curves were adapted to take into account this time-dependent variation of variables. In the case of the 'at least once' achievement, when this was achieved at a specific visit, then the patient remained in this group for all subsequent visits. A p value of $<0.05$ was considered statistically significant. Statistical analyses were performed using SAS (version 8.2 for WindowsTM, Cary, N.C., USA) and STATA (version 8.0, College Station, Tex., USA) software. 
Table 1. Patient clinical characteristics

\begin{tabular}{|c|c|c|c|c|}
\hline Clinical characteristic & $\begin{array}{l}\text { Total } \\
(\mathrm{n}=568)\end{array}$ & $\begin{array}{l}\text { Females } \\
(n=179)\end{array}$ & $\begin{array}{l}\text { Males } \\
(\mathrm{n}=389)\end{array}$ & $\mathrm{p}$ value \\
\hline \multicolumn{5}{|l|}{ General } \\
\hline Age, years & $65.5 \pm 15.2$ & $65.5 \pm 15.8$ & $65.5 \pm 15$ & $>0.99$ \\
\hline Height, $\mathrm{cm}$ & $166.6 \pm 8.5$ & $159.7 \pm 7.3$ & $169.8 \pm 7$ & $<0.0001$ \\
\hline Body weight, kg & $67.9 \pm 15$ & $61.8 \pm 15.1$ & $70.7 \pm 14.1$ & $<0.0001$ \\
\hline $\mathrm{BMI}, \mathrm{kg} / \mathrm{m}^{2}$ & $24.4 \pm 4.9$ & $24.4 \pm 5.7$ & $24.4 \pm 4.5$ & $>0.99$ \\
\hline Dialysis vintage, months & $3.3 \pm 1.7$ & $3.4 \pm 1.7$ & $3.3 \pm 1.8$ & 0.53 \\
\hline \multicolumn{5}{|l|}{ Comorbid diseases } \\
\hline Hypertension, n (\%) & $438(77.1)$ & $141(78.8)$ & $297(76.3)$ & 0.59 \\
\hline Ventricular hypertrophy, n (\%) & $314(55.3)$ & $102(57)$ & $212(54.5)$ & 0.64 \\
\hline Cardiovascular disease, $\mathrm{n}(\%)$ & $226(39.8)$ & $60(33.5)$ & $166(42.7)$ & 0.048 \\
\hline Vascular disease, $\mathrm{n}(\%)$ & $143(25.2)$ & $43(24)$ & $100(25.7)$ & 0.75 \\
\hline Coronary artery disease, $\mathrm{n}(\%)$ & $134(23.6)$ & $30(16.8)$ & $104(26.7)$ & 0.013 \\
\hline Diabetes, $\mathrm{n}(\%)$ & $134(23.6)$ & $47(26.3)$ & $87(22.4)$ & 0.36 \\
\hline Peripheral artery disease, $\mathrm{n}(\%)$ & $106(18.7)$ & $27(15.1)$ & $79(20.3)$ & 0.17 \\
\hline Dyslipidemia, n (\%) & $104(18.3)$ & $34(19)$ & $70(18)$ & 0.86 \\
\hline Cerebrovascular disease, $\mathrm{n}(\%)$ & $71(12.5)$ & $28(15.6)$ & $43(11.1)$ & 0.16 \\
\hline \multicolumn{5}{|l|}{ Biochemical parameters } \\
\hline iPTH, pg/ml & $284.9 \pm 265$ & $330.7 \pm 354.6$ & $264.7 \pm 211.4$ & 0.0061 \\
\hline Serum phosphorus, mg/dl & $5.2 \pm 1.4$ & $5.3 \pm 1.4$ & $5.1 \pm 1.4$ & 0.11 \\
\hline Serum calcium, $\mathrm{mg} / \mathrm{dl}$ & $8.8 \pm 0.8$ & $8.9 \pm 0.8$ & $8.8 \pm 0.8$ & 0.17 \\
\hline Hemoglobin, g/dl & $10.9 \pm 1.2$ & $10.8 \pm 1.3$ & $10.9 \pm 1.2$ & 0.37 \\
\hline Serum albumin, g/dl & $3.5 \pm 0.7$ & $3.5 \pm 0.7$ & $3.5 \pm 0.7$ & $>0.99$ \\
\hline
\end{tabular}

Data presented as mean \pm SD or number and \%. BMI $=$ Body mass index; iPTH = intact parathyroid hormone. $\mathrm{p}$ values represent differences between male and female patients.

\section{Results}

\section{Baseline Clinical Characteristics}

Of the 610 subjects who were eligible for participation in the FARO-2 study, 7 subjects were excluded because they were referred to centers that did not adhere to the project, while 35 were excluded because they had an HD start date earlier than 8 months of the date of study enrollment, therefore not meeting the inclusion criteria. The total sample size was 568 subjects. Of the 568 patients who were included in the first survey (follow-up of 6 months), 128 patients (22.5\%) were observed up to 36 months.

Patient demographic and clinical characteristics at baseline are presented in table 1 . At the start of $\mathrm{HD}$, the average age was 65.5 and $68 \%$ of patients were male. The average duration of $\mathrm{HD}$ recorded at study entry was 3 months. The majority of subjects $(83.1 \%)$ had HD sessions 3 times per week. Most frequent comorbid diseases were hypertension (77\%), ventricular hypertrophy (55.3\%) and cardiovascular disease (39.8\%). Significant differences were observed between male and female patients for some parameters. Besides expected anthropometric differences (height and body weight), male patients had a greater prevalence of cardiovascular disease $(42.7 \%$ vs. $33.5 \%, \mathrm{p}=0.048)$ and coronary artery disease ( $26.7 \%$ vs. $16.8 \%, p=0.013)$ compared to females. In contrast, female patients were observed to have significantly higher baseline serum PTH levels compared to male patients $(330.7 \pm 354.6$ vs. $264.7 \pm 211.4, \mathrm{p}=$ 0.0061).

\section{Levels of MBD Biochemical Parameters}

Levels of serum PTH, Ca and P did not significantly change in patients over the 6 visits (table 2). However, analysis of patients who attended all 6 visits $(n=128)$ revealed a significant increase in serum calcium levels between 6 months and 36 months $(8.9 \pm 0.91$ vs. $8.98 \pm$ $0.64, \mathrm{p}=0.028$ ) (fig. 1a) and concomitant reduction in serum $P$ levels $(5.35 \pm 1.51$ vs. $4.91 \pm 1.3, \mathrm{p}=0.005)$ (fig. 1b). No significant change in serum PTH levels was noted (fig. 1c). 
Table 2. Levels of PTH, $\mathrm{P}$ and $\mathrm{Ca}$

\begin{tabular}{|c|c|c|c|c|c|c|c|c|c|}
\hline $\begin{array}{l}\text { Follow-up time, } \\
\text { months }\end{array}$ & \multicolumn{3}{|c|}{ PTH, pg/ml } & \multicolumn{3}{|c|}{$\mathrm{P}, \mathrm{mg} / \mathrm{dl}$} & \multicolumn{3}{|c|}{$\mathrm{Ca}, \mathrm{mg} / \mathrm{dl}$} \\
\hline 12 & 507 & 197 & $105-324$ & 514 & 5.2 & $4.3-6.0$ & 513 & 8.9 & $8.5-9.3$ \\
\hline 18 & 444 & 201 & $118-332$ & 452 & 5.0 & $4.2-5.8$ & 452 & 8.9 & $8.5-9.3$ \\
\hline 24 & 319 & 212 & $119-315$ & 323 & 4.9 & $4.1-5.8$ & 323 & 9.0 & $8.5-9.3$ \\
\hline
\end{tabular}

$\mathrm{Ca}=$ Serum calcium; $\mathrm{P}=$ serum phosphorus; $\mathrm{PTH}=$ parathyroid hormone; $\mathrm{IQR}=$ interquartile range.

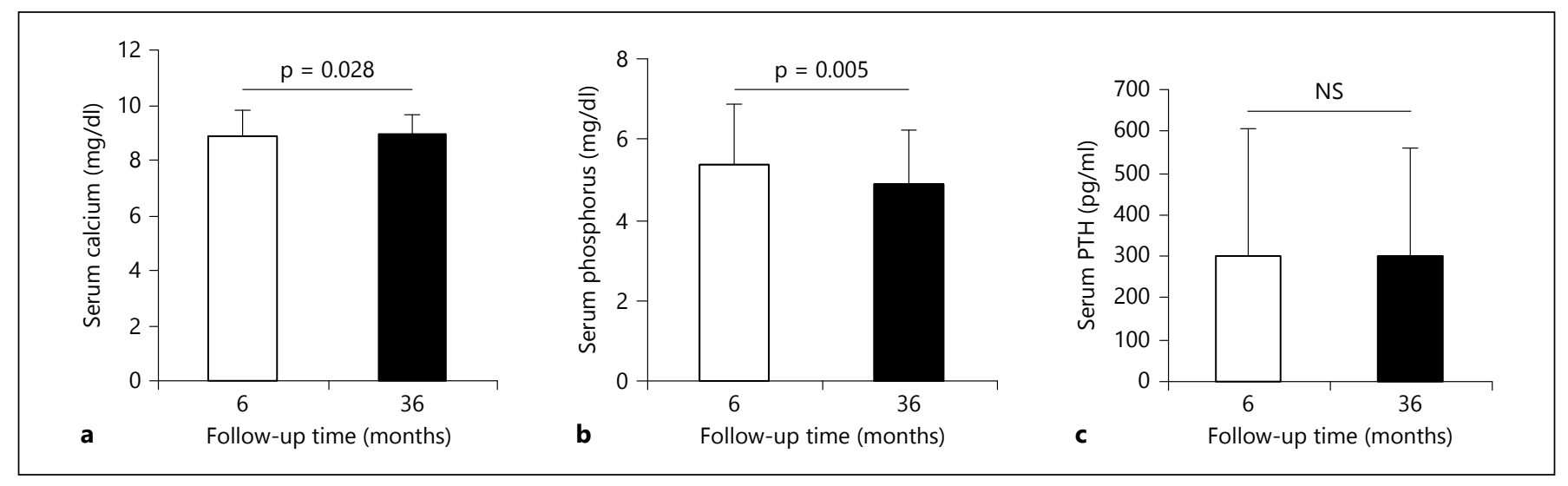

Fig. 1. Levels of biochemical parameters at baseline and follow-up. Levels of Ca (a), P (b) and PTH (c) are shown for patients who attended all visits $(n=128)$. Levels of biochemical parameters are compared between 6 months and 36 months. $p$ values denote statistically significant differences.

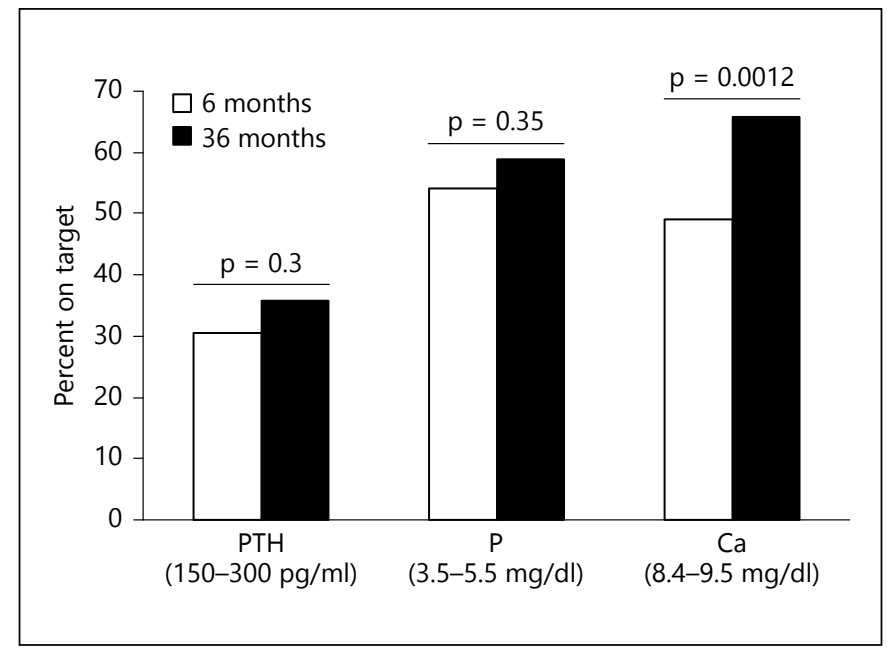

Fig. 2. Proportion of patients achieving target ranges of $\mathrm{PTH}, \mathrm{P}$ and $\mathrm{Ca}$ at 6 months versus 36 months. p values denote statistically significant differences.

\section{MBD Biochemical Parameters and Achievement of K-DOQI Target Values}

The proportion of patients achieving target ranges for PTH, Ca or P increased from the first visit (6 months) to the final visit (36 months), attaining statistical significance for $\mathrm{Ca}$ (fig. 2). The proportion of patients achieving the recommended targets for $\mathrm{PTH}, \mathrm{Ca}$ and $\mathrm{P}$ (all three parameters on target) increased from $8.3 \%$ at baseline to $13.3 \%$ at the end of the follow-up period ( 36 months), this increase just failing to reach statistical significance ( $p=0.086$, table 3$)$. When all semesters were considered together, the proportion of patients increased in a time-dependent manner over the course of the follow-up period (semester 1-6) (Chi-squared for trend $=5.6, p=0.018$ ). We next analyzed the proportion of patients who achieved levels of three biochemical parameters on target at least once during follow-up period. A significant increase was observed in the propor-
40 
Table 3. Patients with three biochemical parameters on target (tritarget)

\begin{tabular}{|c|c|c|c|c|c|}
\hline \multirow{2}{*}{$\begin{array}{l}\text { Follow-up time, } \\
\text { months }\end{array}$} & \multicolumn{2}{|c|}{ Yes } & \multicolumn{2}{|l|}{ No } & \multirow{2}{*}{$\begin{array}{l}\text { Total, } \\
\mathrm{n}\end{array}$} \\
\hline & $\mathrm{n}$ & $\%$ & $\mathrm{n}$ & $\%$ & \\
\hline 6 & 47 & 8.3 & 521 & 91.7 & 568 \\
\hline 12 & 60 & 10.6 & 507 & 89.4 & 567 \\
\hline 18 & 51 & 10.3 & 445 & 89.7 & 496 \\
\hline 24 & 41 & 12.0 & 302 & 88.0 & 343 \\
\hline 30 & 28 & 13.1 & 186 & 86.9 & 214 \\
\hline 36 & 17 & 13.3 & 111 & 86.7 & 128 \\
\hline
\end{tabular}

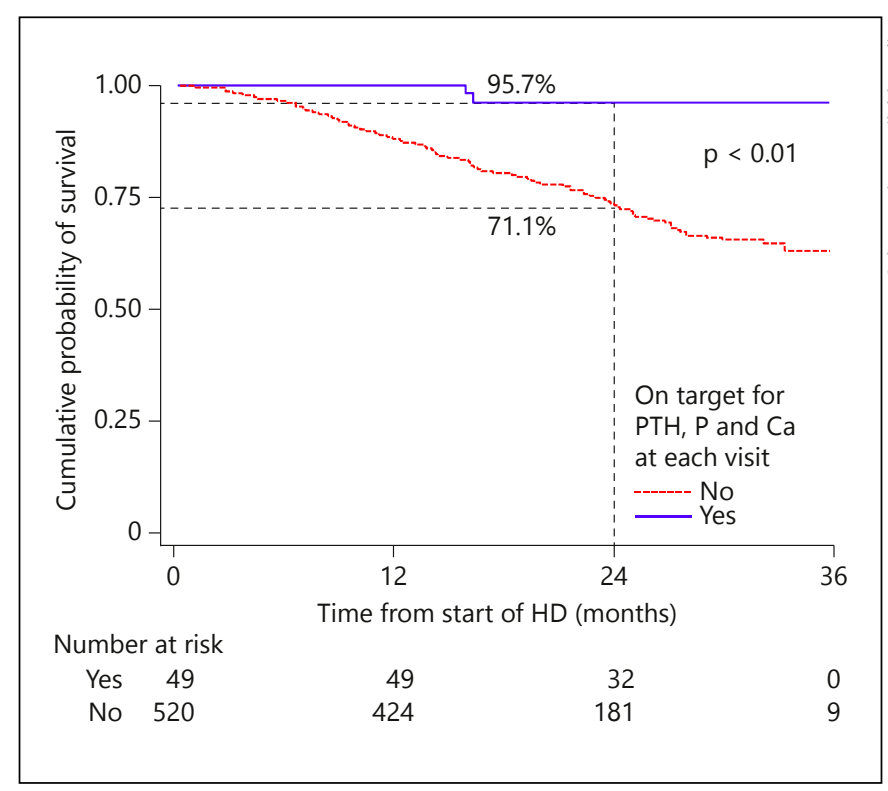

Fig. 3. The Kaplan Meier curve showing the survival rate of patients: tri-target. Survival estimates (all-cause mortality) for FARO-2 patients with three biochemical parameters on target. $\mathrm{HD}=$ Hemodialysis.

tion of patients increasing from baseline to follow-up (30.1 vs. $42.2 \%, \mathrm{p}=0.011$ ) and this increase was observed across all 6 semesters (Chi-squared for trend = $15.1, \mathrm{p}=0.0001)($ table 4$)$.

\section{Survival in Patients on Target for MBD Biochemical Parameters}

The survival rate at the end of the study was higher in incident HD patients on target for the three MBD parameters (tri-target) compared to patients off target (survival at 24 months: at target $95.7 \%$ (95\% CI: 84.0-98.9) versus not at target $71.1 \%$ (95\% CI: 66.3-75.4, p < 0.01))
Table 4. Patients with three biochemical parameters on target at least once during follow-up

\begin{tabular}{|c|c|c|c|c|c|}
\hline \multirow{2}{*}{$\begin{array}{l}\text { Follow-up time, } \\
\text { months }\end{array}$} & \multicolumn{2}{|l|}{ Yes } & \multicolumn{2}{|l|}{ No } & \multirow{2}{*}{$\begin{array}{l}\text { Total, } \\
\mathrm{n}\end{array}$} \\
\hline & $\mathrm{n}$ & $\%$ & $\mathrm{n}$ & $\%$ & \\
\hline 6 & 171 & 30.1 & 397 & 69.9 & 568 \\
\hline 12 & 171 & 30.2 & 396 & 69.8 & 567 \\
\hline 18 & 164 & 33.1 & 332 & 66.9 & 496 \\
\hline 24 & 132 & 38.5 & 211 & 61.5 & 343 \\
\hline 30 & 83 & 38.8 & 131 & 61.2 & 214 \\
\hline 36 & 54 & 42.2 & 74 & 57.8 & 128 \\
\hline
\end{tabular}

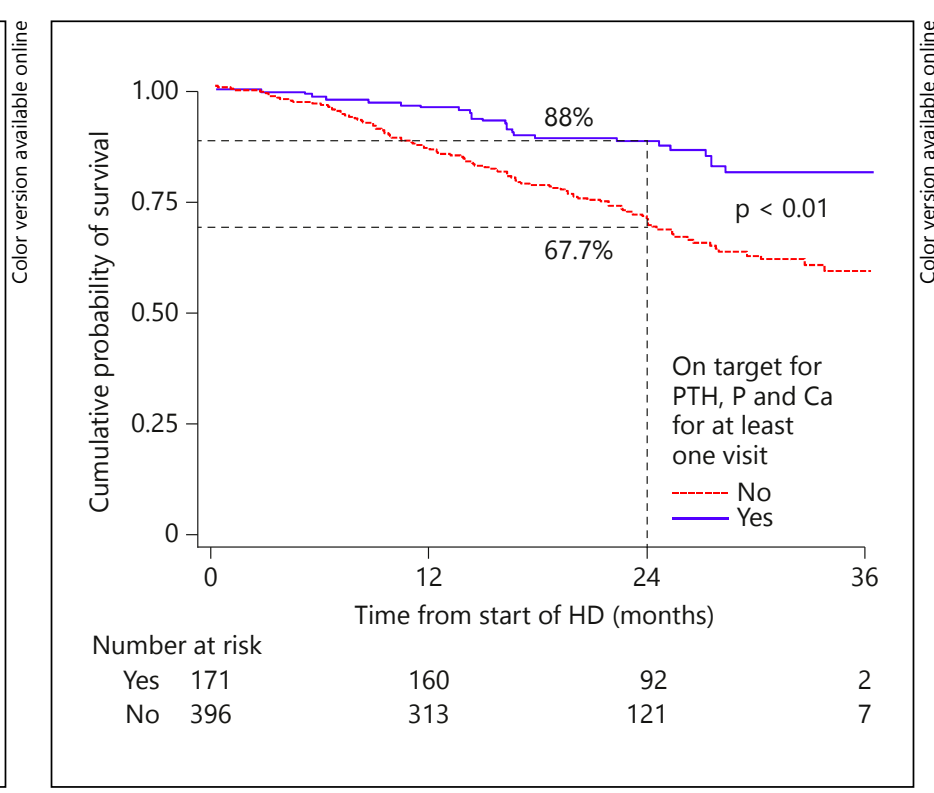

Fig. 4. The Kaplan Meier curve showing the survival rate of patients: tri-target. Survival estimates (all-cause mortality) for FARO-2 patients with three biochemical parameters on target at least once during the 36 months. $\mathrm{HD}=$ Hemodialysis.

(fig. 3). The time course presented in figure 3 shows that the event curves for patients on target for the three MBD parameters compared with those patients not on target had already separated as early as 6 months (clearly separating at 1 year), and continued to further diverge for the duration of the study. The proportion of patients on target for the three MBD parameters (30.1\%) at least once during the 36 months of follow-up (see table 4) showed a better survival rate compared to those that never reached these targets (survival at 24 months: at least once 88.0\% (95\% CI: 81.9-92.1); 67.7\% (95\% CI: 61.9-72.8, $\mathrm{p}<0.01))$ (fig. 4). 


\section{Discussion}

Previous studies have examined the effects of elevated $\mathrm{Ca}, \mathrm{P}$ and PTH levels on mortality in hemodialysis patients $[3-6,8-15,19,31,32,39]$. Although this analysis has also been extended to incident hemodialysis patients $[33,34]$, only a few studies have been conducted to date and none of these have been performed in Italy.

In this analysis of the FARO-2 study, we show that mortality rates at 24 months are associated with a reduction by as much as $25 \%$ in patients who achieved target ranges for three of the bone and mineral parameters $(\mathrm{Ca}$, $\mathrm{P}$ and $\mathrm{PTH}$ ) according to K/DOQI guidelines. Moreover, by attaining target ranges for the three parameters at least once over the survey, survival rates were still $20 \%$ greater than those never achieving the K/DOQI targets. The findings from our survival analysis support these previous studies and more importantly, extend our knowledge by demonstrating that the achievement of KDOQI targets over time is associated with a significant improvement in survival.

In our original FARO study [36], approximately twothirds of all patients failed to achieve target PTH levels and nearly $90 \%$ failed to achieve the combined target of $\mathrm{PTH}, \mathrm{P}$, and Ca levels according to K/DOQI guidelines [17]. Likewise, in this analysis of the FARO-2 study, approximately $90 \%$ of patients failed to achieve combined and sustained target ranges. Although survival analysis emerging from our study underline that sustained achievement of combined target ranges over time is not essential to overall survival improvement (20\% vs. $25 \%$ ), collectively, these data indicate that the achievement of $\mathrm{K} / \mathrm{DOQI}$ target ranges may be difficult for many CKD patients with SHPT. With this in mind, we also performed a retrospective analysis to determine how patients fared in terms of achievement of target ranges according to the newer KDIGO guidelines [38]. It is important to underline that while the target ranges for Stage 5 CKD HD patients for iPTH concentrations are $150-300 \mathrm{pg} / \mathrm{ml}$ according to K/DOQI guidelines [17], the newer KDIGO guidelines recommend maintaining PTH levels 2-9-fold the upper normal limit [38], corresponding to a range of $130-600 \mathrm{pg} / \mathrm{ml}$ [40]. As we would have expected, by following KDIGO guidelines the number of patients on target was increased. While only $35.9 \%$ of patients were on target for PTH levels according to K/DOQI guidelines, this proportion increased to $63 \%$ when KDIGO guidelines were adopted (see online suppl. table 1; for all online suppl. material, see www.karger.com/doi/10.1159/000365386). Likewise, the proportion of patients with three biochemical parameters on target (tri-target) at least once was higher for KDIGO (46\%) compared to K/DOQI guidelines $(30.1 \%)$ and in patients who attained tri-target for all 6 visits (25.8\% for KDIGO vs. $13.3 \%$ for K/DOQI; online suppl. table 2). Since KDIGO guidelines are less restrictive, a greater proportion of patients will likely have more severe hyperparathyroidism. Therefore, it was not surprising that our analysis also revealed a higher mortality rate in those patients who were never on target according to KDIGO ranges (46\%) compared to K/ DOQI (29.7\%). Our findings indicate that while a reassessment of K/DOQI target ranges may be warranted to determine if they are perhaps too strict, tentative evidence from our retrospective analysis suggests that the newer KDIGO guidelines, particularly for the PTH range, are possibly too relaxed. Actually, a recent prospective observational study performed on 8,377 prevalent patients receiving intermittent hemodialysis therapy in France examined the association between mortality and serum concentrations of phosphate, calcium and PTH through KDIGO target ranges [41]. They concluded that a 'grey zone' exists where the precise biochemical targets are difficult to define, with the exception of avoiding extreme values. KDIGO did not recommend precise threshold values, but rather 'normal' laboratory values, which may differ from one PTH kit to another. This study also confirmed the relative risk of low iPTH values, as proposed by KDIGO recommendations [41-52].

One of the difficulties in achieving multiple K/DOQI targets consistently is that the majority of treatment approaches reflect a compromise between controlling PTH and controlling $\mathrm{Ca}$ and $\mathrm{P}$ [42]. Although newer therapies such as paricalcitol [43-47], as well as combined calcimimetic and VDRA therapy have been shown to enhance the ability of patients reaching KDOQI target values for biochemical parameters [48], their long-term safety and efficacy, and ultimately mortality rates, still needs to be verified in randomized controlled trials. The IMPACT study, a randomized controlled trial performed on 272 patients with SHPT on maintenance HD was recently undertaken with the aim of examining the efficacy and safety of paricalcitol compared to cinacalcet [49]. In this 28week, multicenter, open-label Phase 4 study, participants received paricalcitol or cinacalcet plus low-dose vitamin D. Findings from this study revealed overall superiority of paricalcitol $(56 \%)$ over cinacalcet $(38.2 \%$; $p=0.01)$ in the proportion of patients achieving PTH $150-300 \mathrm{pg} / \mathrm{ml}$
Cozzolino et al. 
[49]. Long-term randomized controlled trials are still needed to determine the extent that these therapies, administered in combination or as monotherapy provide survival benefit.

Two other studies have been performed to date that have examined the achievement of K/DOQI guidelines on incident HD patients $[33,34]$. Although both studies had a large sample size (7,076 and 22,937 respectively), the follow-up period was only for 2 years. The proportion of patients achieving K/DOQI target ranges for individual mineral parameters was marginally less than what we observed for FARO-2 and these differences may be attributed to the difference in the follow-up period, heterogeneous population $(75 \%$ of patients were incident HD in study by Tangri) [33] and a substantial proportion of patients were managed prior to $2003 \mathrm{~K} / \mathrm{DOQI}$ updates.

One finding that emerged from our analysis was that female subjects had significantly elevated serum PTH levels at the first visit compared to their male counterparts. It is recognized that osteoporosis is more prevalent among women than among men and abnormalities in iPTH secretion play an important role in bone loss. Thus, hypersecretion of iPTH might be expected to be more pronounced in women than in men. An observational study by Haden and colleagues (2000) [50] demonstrated that the levels of serum PTH were higher in elderly women compared to elderly men. Although this study was performed on a healthy control population, perhaps these findings could be extended to patients with CKD. Indeed, in young healthy females, serum vitamin D levels can be lower than male subjects; this may be attributed to the differences in factors such as hormonal, muscle mass and bone density [51]. Interestingly, additional analysis of survival rates stratified by gender did not reveal any significant difference. This would imply that survival benefit in terms of patients attaining $\mathrm{K} / \mathrm{DOQI}$ target ranges is distributed equally by gender, regardless of differences in biochemical parameters at baseline.

\section{Study Limitations}

Although findings from this analysis of the FARO-2 study provide clinical insights on the importance of attaining target ranges in incident HD patients, some weaknesses of this study do need to be addressed. Even though the number of patients at baseline was relatively large $(\mathrm{n}=$ 568 ), only a fraction of this population (one-quarter) attended all visits during the entire follow-up period ( $\mathrm{n}=$ 128). Our analysis was based on all patients and as such does not correct for changes in characteristics of patients who entered or left the study. However, we have also performed additional sub-analysis on patients attending all visits and observed a similar proportion of patients achieving K/DOQI target ranges. For some parameters (e.g., PTH), values were missing for some patients during the follow-up period as they were not requested by the nephrologist to be present or they were absent from the CRF. Target ranges for biochemical parameters were based on the 2003 guidelines of the Kidney Disease Outcomes Quality Initiative (K/DOQI) of the National Kidney Foundation [17], since the 2009 Kidney Disease Improving Global Outcomes (KDIGO) guidelines were not yet available when this study was undertaken [38]. Despite the availability of the newer KDIGO guidelines, the majority of clinical practice still employs the KDOQI recommendations, thus maintaining the clinical relevance of the present findings. Visits were conducted every 6 months. More frequent visits (e.g., monthly) may have provided more detailed information with regard to associations between therapeutic management and changes in biochemical and mineral parameters. Regardless of these study limitations, several strengths of the FARO-2 study are worth highlighting. Our survey was based on an observation over a long period of time (36 months) on incident CKD patients undergoing HD treatment and to our knowledge is the longest follow-up period conducted to date examining the achievement of K/DOQI targets on survival. Second, FARO-2 was a multicentric study, ensuring our findings are representative of the entire Italian HD population.

\section{Conclusion}

Findings from FARO-2 indicate that control of the three bone and mineral metabolism markers PTH, $\mathrm{P}$ and Ca within target ranges recommended by KDOQI guidelines is associated with improved survival in incident HD patients, compared with controlling fewer markers. Although only $8 \%$ of patients were able to achieve K/DOQI targets for all three bone and mineral metabolism markers (30\% achieved K/DOQI targets at least once over the study period), this equated to a notable $25 \%$ increase in survival after 2 years. However, considering the limitations of this observational design, the benefit of achieving K/DOQI targets, and the more recent KDIGO targets, on survival in incident HD patients still remains to be confirmed in long-term prospective randomized clinical trials. 


\section{Acknowledgments}

The authors would like to thank the FARO study group: Mario Bonomini (Chieti), Giovanni Cancarini (Brescia), Maria Rosa Caruso (Bergamo), Andrea Galfrè (Cagliari), Loreto Gesualdo (Bari), Cosimo Lodeserto (Taranto), Fabio Malberti (Cremona), Martino Marangella (Torino), Massimo Morosetti (Ostia Lido), Francesco Quarello (Torino), Giuseppe Rombolà (La Spezia), Sergio Stefoni (Bologna). We would also like to thank Dr Colin Gerard Egan (Primula Multimedia SRL, Pisa Italy) for medical writing assistance (funded by AbbVie).

\section{Disclosure Statements}

Mario Cozzolino - FARO Steering Committee. Lecture honoraria from Abbott, Shire, Amgen, Genzyme, Roche.

Piergiorgio Messa - FARO Steering Committee. Lecture honoraria from Janssen Cilag, Amgen.
Diego Brancaccio - FARO Steering Committee. Consultant for Abbott; lecture honoraria from GSK, Amgen and Shire.

Giuseppe Cannella - FARO Steering Committee. Lecture honoraria from Abbott.

Piergiorgio Bolasco - FARO Study Group member - Lecture honoraria from Abbott.

Marina Di Luca - FARO Study group member - Lecture honoraria from Abbott, Shire, Amgen, Genzyme.

Anna Maria Costanzo - Abbvie Italy Head Medical Affairs $\mathrm{SH}$.

Umberto di Luzio Paparatti - Abbvie Italy Affiliate Medical Director.

Vincenzo Festa - AbbVie Italy Medical Manager.

Giuliana Gualberti - AbbVie Italy Biometrics and Compliance Manager.

Sandro Mazzaferro - FARO Steering Committee. Lecture honoraria from Shire and Amgen.

This study was sponsored by AbbVie. AbbVie contributed to the study design, research, and interpretation of data, writing, reviewing, and approving the publication.

\section{References}

1 Foley RN, Parfrey PS, Sarnak MJ: Clinical epidemiology of cardiovascular disease in chronic renal disease. Am J Kidney Dis 1998; 32(suppl 3):S112-S119.

2 Iseki K, Shinzato T, Nagura Y, Akiba T: Factors influencing long-term survival in patients on chronic dialysis. Clin Exp Nephrol 2004;8:89-97.

3 Block GA, Hulbert-Shearon TE, Levin NW, et al: Association of serum phosphorus and calcium $\mathrm{x}$ phosphate product with mortality risk in chronic hemodialysis patients: a national study. Am J Kidney Dis 1998;31:607-617.

$\checkmark 4$ Stevens LA, Djurdjev O, Cardew S, et al: Calcium, phosphate, and parathyroid hormone levels in combination and as a function of dialysis duration predict mortality: evidence for the complexity of the association between mineral metabolism and outcomes. J Am Soc Nephrol 2004;15:770-779.

5 Block GA, Klassen PS, Lazarus JM, et al: Mineral metabolism, mortality, and morbidity in maintenance hemodialysis. J Am Soc Nephrol 2004;15:2208-2218.

6 Slinin Y, Foley RN, Collins AJ: Calcium, phosphorus, parathyroid hormone, and cardiovascular disease in hemodialysis patients: the USRDS waves 1, 3, and 4 study. J Am Soc Nephrol 2005;16:1788-1793.

7 Kestenbaum B, Sampson JN, Rudser KD, et al: Serum phosphate levels and mortality risk among people with chronic kidney disease. J Am Soc Nephrol 2005; 16:520-528.

8 Young EW, Albert JM, Satayathum S, et al: Predictors and consequences of altered mineral metabolism: the Dialysis Outcomes and Practice Patterns Study. Kidney Int 2005;67:1179-1187.

-9 Kalantar-Zadeh K, Uwae N, Regidor DL, et al: Survival predictability of time-varying indica- tors of bone disease in maintenance hemodialysis patients. Kidney Int 2006;70:771-780.

10 Wald R, Sarnak MJ, Tighiouart H, et al: Disordered mineral metabolism in hemodialysis patients: an analysis of cumulative effects in the Hemodialysis (HEMO) Study. Am J Kidney Dis 2008;52:531-540.

11 Tentori F, Blayney MJ, Albert JM, et al: Mortality risk for dialysis patients with different levels of serum calcium, phosphorus, and PTH: the Dialysis Outcomes and Practice Patterns Study (DOPPS). Am J Kidney Dis 2008;52:519-530.

12 Floege J, Kim J, Ireland E, et al; on behalf of the ARO Investigators: Serum iPTH, calcium and phosphate, and the risk of mortality in a European haemodialysis population. Nephrol Dial Transplant 2011;26:1948-1955.

13 Nakai S, Akiba T, Kazama J, Yokoyama K, Fukagawa M, Tominaga Y, Iseki K, Tsubakihara Y; Patient Registration Committee of the Japanese Society for Dialysis Therapy, Tokyo, Japan: Effects of serum calcium, phosphorous, and intact parathyroid hormone levels on survival in chronic hemodialysis patients in Japan. Ther Apher Dial 2010;12:49-54.

14 Naves-Díaz M, Passlick-Deetjen J, Guinsburg A, Marelli C, Fernández-Martín JL, Rodríguez-Puyol D, Cannata-Andía JB: Calcium, phosphorus, $\mathrm{PTH}$ and death rates in a large sample of dialysis patients from Latin America. The CORES Study. Nephrol Dial Transplant 2011;26:1938-1947.

15 Cozzolino M, Brancaccio D, Cannella G, Messa P, Gesualdo L, Marangella M, LoDeserto C, Pozzato M, Rombolà G, Costanzo AM, di Luzio Paparatti U, Mazzaferro S; FARO Study Group: VDRA therapy is associated with improved survival in dialysis pa- tients with serum intact PTH $\leq 150 \mathrm{pg} / \mathrm{ml}$ : results of the Italian FARO survey. Nephrol Dial Transplant 2012;27:3588-3594.

16 Martin KJ, Gonzalez EA: Metabolic bone disease in chronic kidney disease. J Am Soc Nephrol 2007;18:875-885.

17 National Kidney Foundation: K/DOQI Clinical Practice Guidelines for Bone Metabolism and Disease in Chronic Kidney Disease. Am J Kidney Dis 2003;42:S1-S202.

18 Wei M, Taskapan H, Esbaei K, Jassal SV, Bargman JM, Oreopulos DG: K/DOQI guideline requirements for calcium, phosphate, calcium phosphate product, and parathyroid hormone control in dialysis patients: can we achieve them? Int Urol Nephrol 2006;38:739-743.

19 Young EW, Akiba T, Albert JM, et al: Magnitude and impact of abnormal mineral metabolism in hemodialysis patients in the Dialysis Outcomes and Practice Patterns Study (DOPPS). Am J Kidney Dis 2004;44:34-38.

20 Toussaint ND, Pedagogos E, Beavis J, et al Improving CKD-MBD management in haemodialysis patients: barrier analysis for implementing better practice. Nephrol Dial Transplant 2011;26:1319-1326.

21 Brown AJ, Slatopolsky E: Drug insight: vitamin D analogs in the treatment of secondary hyperparathyroidism in patients with chronic kidney disease. Nat Clin Pract Endocrinol Metab 2007;3:134-144.

22 Ronco C, Cozzolino M: Mineral metabolism abnormalities and vitamin $\mathrm{D}$ receptor activation in cardiorenal syndromes. Heart Fail Rev 2012;17:211-220.

23 Khan S: Vitamin D deficiency and secondary hyperparathyroidism among patients with chronic kidney disease. Am J Med Sci 2007; 333:201-207. 
24 Teng M, Wolf M, Lowrie E, Ofsthun N, Lazarus JM, Thadhani R: Survival of patients undergoing hemodialysis with paricalcitol or calcitriol therapy. N Engl J Med 2003;349: 446-456.

25 Teng M, Wolf M, Ofsthun MN, et al: Activated injectable vitamin $\mathrm{D}$ and hemodialysis survival: a historical cohort study. J Am Soc Nephrol 2005;16:1115-1125.

26 Kalantar-Zadeh K, Kuwae N, Regidor DL, Kovesdy CP, Kilpatrick RD, Shinaberger CS, McAllister CJ, Budoff MJ, Salusky IB, Kopple JD: Survival predictability of time-varying indicators of bone disease in maintenance hemodialysis patients. Kidney Int 2006;70:771780.

27 Naves-Díaz M, Alvarez-Hernández D, PasslickDeetjen J, Guinsburg A, Marelli C, RodriguezPuyol D, Cannata-Andía JB: Oral active vita$\mathrm{min} \mathrm{D}$ is associated with improved survival in hemodialysis patients. Kidney Int 2008;74: 1070-1078.

28 Wolf M, Betancourt J, Chang Y, Shah A, Teng M, Tamez H, Gutierrez O, Camargo CA Jr, Melamed M, Norris K, Stampfer MJ, Powe NR, Thadhani R: Impact of activated vitamin $\mathrm{D}$ and race on survival among hemodialysis patients. J Am Soc Nephrol 2008;19:13791388.

29 Tentori F, Albert JM, Young EW, Blayney MJ, Robinson BM, Pisoni RL, Akiba T, Greenwood RN, Kimata N, Levin NW, Piera LM, Saran R, Wolfe RA, Port FK: The survival advantage for $H D$ patients taking vitamin $\mathrm{D}$ is questioned: findings from the Dialysis Outcomes and Practice Patterns Study. Nephrol Dial Transplant 2009;24:963-972.

- 30 Ogawa T, Kyono A, Sato M, Sugimoto H, Otsuka K, Nitta K: Vitamin D receptor agonist supplementation and suppression of inflammation may have advantage for all-cause mortality in hemodialysis patients. Clin Exp Nephrol 2012;16:779-785.

- 31 Brancaccio D, Cozzolino M, Cannella G, Messa P, Bonomini M, Cancarini G, Caruso MR, Cascone C, Costanzo AM, di Luzio Paparatti U, Mazzaferro S; on behalf of the FARO Study Group: Secondary hyperparathyroidism in chronic dialysis patients: results of the Italian FARO survey on treatment and mortality. Blood Purif 2011;32:124-132.

- 32 Palmer SC, Hayen A, Macaskill P, Pellegrini F, et al: Serum levels of phosphorus, parathyroid hormone, and calcium and risks of death and cardiovascular disease in individuals with chronic kidney disease: a systematic review and meta-analysis. JAMA 2011;16:1119-1127.
33 Tangri N, Wagner M, Griffith JL, et al: Effect of bone mineral guideline target achievement on mortality in incident dialysis patients: an analysis of the United Kingdom Renal Registry. Am J Kidney Dis 2011;57:415-421.

34 Danese MD, Belozeroff V, Smirnakis K, Rothman KJ: Consistent control of mineral and bone disorder in incident hemodialysis patients. Clin J Am Soc Nephrol 2008;3:14231429.

35 Bradbury BD, Fissell RB, Albert JM, et al: Predictors of early mortality among incident US hemodialysis patients in the Dialysis Outcomes and Practice Patterns Study (DOPPS). Clin J Am Soc Nephrol 2007;2:89-99.

- 36 Mazzaferro S, Brancaccio D, Messa P, Andreucci VE, Bellinghieri G, Bigazzi R, Bolasco P, Costanzo AM, di Luzio Paparatti U, Cannella G; on behalf of the FARO Study Group: Management of secondary hyperparathyroidism in Italy: results of the Italian FARO survey. J Nephrol 2011;24:225-235.

37 Cozzolino M, Messa P, Brancaccio D, Cannella G, Mazzaferro S; and the FARO-2 Study Group: Achievement of the NKF/K-DOQI recommended target values for bone and mineral metabolism in incident haemodialysis patients: results of the FARO-2 cohort. Abstracts of the 49th ERA-EDTA (European Renal Association - European Dialysis and Transplant Association) Congress. May 2427, 2012. Paris, France. Nephrol Dial Transplant 2012;27(suppl 2):iil-ii536. Abstract number 565 .

38 KDIGO clinical practice guideline for the diagnosis, evaluation, prevention, and treatment of chronic kidney disease-mineral and bone disorder (CKD-MBD). Kidney Int 2009; 76(suppl 113):S1-S130.

39 Ganesh SK, Stack AG, Levin NW, HulbertShearon T, Port FK: Association of elevated serum $\mathrm{PO}(4), \mathrm{Ca} \times \mathrm{PO}(4)$ product, and parathyroid hormone with cardiac mortality risk in chronic hemodialysis patients. J Am Soc Nephrol 2001;12:2131-2138.

40 Uhlig K, Berns JS, Kestenbaum B, et al: KDOQI US commentary on the 2009 KDIGO clinical practice guideline for the diagnosis, evaluation, and treatment of CKD-mineral and bone disorder (CKD-MBD). Am J Kidney Dis 2010;55:773-799.

41 Fouque D, Roth H, Pelletier S, et al: Control of mineral metabolism and bone disease in haemodialysis patients: which optimal targets? Nephrol Dial Transplant 2013;28:360-367.

42 Arenas MD, Alvarez-Ude F, Torregrosa V, et al: Consequences of the implementation of ' $\mathrm{K} /$ DOQI Clinical Practice Guidelines for Bone Metabolism and Disease in Chronic Kidney Disease' in a population of patients on chronic hemodialysis. J Nephrol 2007;20:453-461.
43 Hervás Sánchez JG, Prados Garrido MD, Polo Moyano A, Cerezo Morales S: Effectiveness of treatment with oral paricalcitol in patients with pre-dialysis chronic kidney disease. $\mathrm{Ne}$ frologia 2011;31:697-706.

44 Mittman N, Desiraju B, Meyer KB, Chattopadhyay J, Avram M: Treatment of secondary hyperparathyroidism in ESDR: a 2-year, single-center crossover study. Kidney Int 2010; 78(suppl 117):S33-S36.

45 Capuano A, Serio V, Pota A, et al: Beneficial effects of better control of secondary hyperparathyroidism with paricalcitol in chronic dialysis patients. J Nephrol 2009;22:59-68.

46 Ross EA, Tian J, Abboud H, et al: Oral paricalcitol for the treatment of secondary hyperparathyroidism in patients on hemodialysis or peritoneal dialysis. Am J Nephrol 2008;28: 97-106.

47 Llach F, Yudd M: Paricalcitol in dialysis patients with calcitriol resistant secondary hyperparathyroidism. Am J Kidney Dis 2001; 38:S45-S50.

48 Block GA, Zeig S, Sugihara J, et al; TARGET Investigators: Combined therapy with cinacalcet and low doses of vitamin D sterols in patients with moderate to severe secondary hyperparathyroidism. Nephrol Dial Transplant 2008;23:2311-2318.

49 Ketteler M, Martin KJ, Wolf M, et al: Paricalcitol versus cinacalcet plus low-dose vitamin D therapy for the treatment of secondary hyperparathyroidism in patients receiving haemodialysis: results of the IMPACT SHPT study. Nephrol Dial Transplant 2012; 27:3270-3278.

50 Haden ST, Brown EM, Hurwitz S, Scott J, ElHajj Fuleihan G: The effects of age and gender on parathyroid hormone dynamics. Clin Endocrinol (Oxf) 2000;52:329-338.

51 Gorini A, Costanzo AM, Egan CG, di Luzio Paparatti U: Renal status in adult volunteers in central Italy: results from Family Abbott Renal Disease Monitoring Project (FARM) study. J Nephrol 2012;25:523-532.

52 Fernández-Martín JL, Carrero JJ, Benedik M, Jan Bos W, Covic A, Ferreira A, Jürgen Floege J, Goldsmith D, Gorriz JL, Ketteler M, Kramar R, Locatelli F, London G, Martin PY, Memmos D, Nagy J, Naves-Díaz M, Pavlovic D, Rodríguez-García M, Rutkowski B, Teplan V, Tielemans C, Verbeelen D, Wüthrich RP, Martínez-Camblor P, Cabezas-Rodriguez I, Sánchez-Alvarez JE, Cannata-Andia JB: COSMOS: the dialysis scenario of CKDMBD in Europe. Nephrol Dial Transplant 2012;0:1-11.
NKF/K-DOQI Recommended Target Values
Blood Purif 2014;38:37-45 DOI: $10.1159 / 000365386$ 